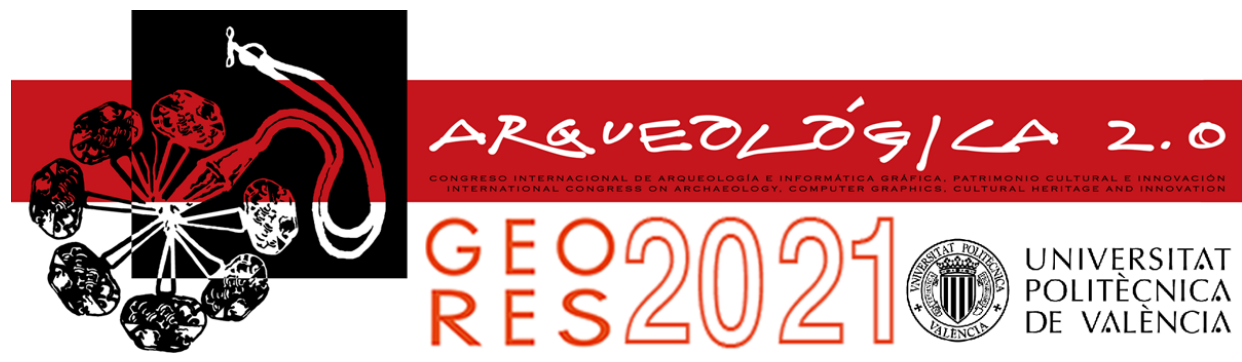

Proceedings of the joint international event $9^{\text {th }}$ ARQUEOLÓGICA

$2.0 \& 3^{\text {rd }}$ GEORES

Valencia (Spain).

26-28 April 2021

\title{
DOCUMENTATION OF A COMPLEX CULTURAL HERITAGE ASSET WITH INTEGRATED GEOMATIC SURVEY: THE MONTANARO BELL TOWER
}

\author{
Lorenzo Teppati Losè ${ }^{a,},{ }^{,}$Filiberto Chiabrando ${ }^{a}$, Francesco Novelli ${ }^{b}$, Giacomo Patrucco ${ }^{a}$, Stefano \\ Perria \\ a Laboratory of Geomatics for Cultural Heritage. Department of Architecture and Design (DAD), Politecnico di Torino, Viale Mattioli 39, \\ 10125 Torino, Italy. Iorenzo.teppati@polito.it; filiberto.chiabrando@polito.it; giacomo.patrucco@polito.it; stefano.perri@polito.it \\ b Department of Architecture and Design (DAD), Politecnico di Torino, Viale Mattioli 39, 10125 Torino, Italy. francesco.novelli@polito.it
}

\begin{abstract}
:
The research activities presented in this manuscript are focused on the documentation of a valuable built heritage asset: the Santa Marta bell tower (1769-1772), designed by the Italian architect Bernardo Antonio Vittone and located in the municipality of Montanaro (30 km North-East of Turin, Italy). The documentation of this complex palimpsest was designed to meet the requirements of the decay analysis and to provide a reference for the future restoration and valorisation project. To achieve these objectives a multi-scale and multi-sensor survey was designed and carried out exploiting several geomatics techniques (both range and image-based). The fieldwork activities were firstly dedicated to the creation and measurement of a reference topographic network to be used as a common local reference system for all the acquisitions as well as a series of control points (both inside and outside the bell tower) to be used for data orientation and accuracy assessment. Secondly, the exterior of the bell tower and its surroundings were imaged by means of an Unmanned Aerial Vehicle (UAV) and a set of Terrestrial Laser Scanning (TLS) acquisitions. The interior of the bell tower was acquired with two different rapid mapping approaches: using a handheld laser scanner based on the Simultaneous Localisation And Mapping (SLAM) technology and two different $360^{\circ}$ cameras. All the acquired data were processed following both consolidated and experimental approaches and then integrated to generate traditional 2D architectural drawings supported by added value metric products. Of particular interest are the tests connected with the processing of the SLAM data and $360^{\circ}$ images using a spherical photogrammetric approach that delivered preliminary encouraging results.
\end{abstract}

Keywords: built heritage, SfM, spherical photogrammetry, SLAM, multi-sensor, multi-scale

\section{Introduction and historical background}

Geomatics techniques are nowadays able to create threedimensional (3D) models in order to document extensive complexes or specific objects at a different scale. A 3D model in form of a point cloud or mesh could provide a useful base on which other products and further analyses can be extracted and carried out in the cultural heritage domain especially when different actors are involved (historian, restorers etc). In this scenario, the range-based and image-based techniques integrated with traditional topographic measurements could be considered as consolidated methodologies that can provide all the geometric information useful for architectural documentation. In the last years, two interesting new approaches related to the aforementioned techniques are even more employed for architectural surveys in complex environments (narrow areas or articulated spaces). These instruments are the handled laser scanner based on SLAM algorithms and $360^{\circ}$ cameras. Those sensors have been employed and integrated with UAV photogrammetry and TLS for the 3D survey of a very challenging structure: the municipality bell tower of Montanaro, a little village close to Torino in Piedmont (Italy). The bell tower, the old town hall, the brotherhood of S. Marta and the parish church form an indivisible whole in Montanaro, which well expresses the ideal integration between the secular community and the sacred space in a small eighteenth-century 'civic center' (Fig. 1). The fulcrum of the composition is the bell tower, about $48 \mathrm{~m}$ high. Built together with the municipal house between 1769 and 1772, on a project by Bernardo Antonio Vittone, it was the result of a complicated survey, in which the architect examined five different possible arrangements for the tower, in the space of a few tens of meters (Battaglio, 2000)

The lightening of the building towards the top and the decorative progression characterize the work, which becomes slender and jagged towards the top. A stone spiral staircase develops inside. The tower was built under the guidance of Mario Ludovico Quarini, who inherited the site after Vittone's death in 1770. 


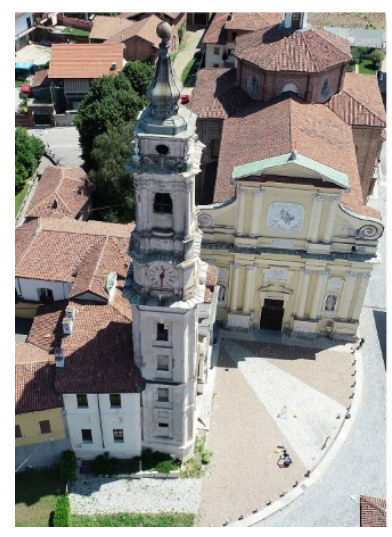

(a)

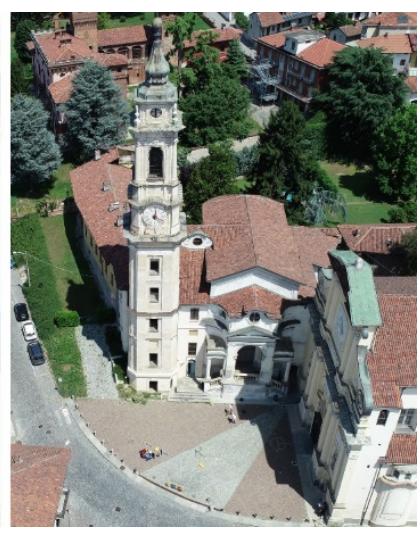

(b)
Figure 1: Aerial views of the bell tower and the complex of buildings around: a) west view; b) south view.

The bell tower is an ambitious work, which makes use of models and experiences accumulated over a lifetime of work (Canavesio, 2005; Portoghesi, 1966). Already prefigured in the projects designed in Rome in the 1730s, the Montanaro tower is indebted to similar projects by Juvarra, but also takes into account the experiences of Benedetto Alfieri. The latter, in fact, had set up very tall bell towers in Novara and Carignano a few years earlier. The construction is documented by a rare set of original drawings still preserved in Montanaro, which include plans, sections, elevations, and several 1:1 scale drawings of the main mouldings (two examples are shown in Figure 2). An original drawing for the Montanaro bell tower is also kept in Berlin, in the collections of the Art Library.

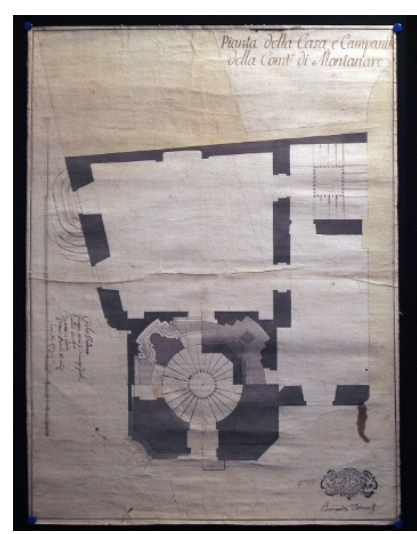

(a)

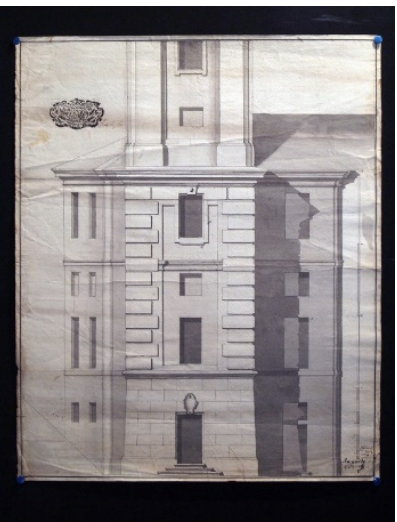

(b)
Figure 2: Two images of the drawings (Historical Archive of Montanaro) carried out by B. A. Vittone: a) the bell tower plan (27th of August 1769- left); b) the main façade (1769-1772).

\section{The documentation project and field acquisitions}

Due to the high complexity of the heritage asset to be surveyed, it was necessary to carefully design all the phases of the documentation project to achieve a 1:100 nominal map scale (accuracy for a 1:100 nominal scale should be under $0.02 \mathrm{~m}$ with a tolerance of $0.04 \mathrm{~m}$ ). This necessity was fulfilled through a preliminary on-site visit and a study of the already existing materials (e.g. drawings, images, etc.) available for the bell tower and a careful design of the survey operations and techniques adopted.

The first task was the setup and measurement of the topographic network to create a common reference network referenced to a global coordinate system with a 3D accuracy of few millimeters, fitting the requirements of a 1:100 nominal map scale. A total of five vertices were created and measured on the area in front of the tower and three additional vertices were materialized on some of the intermediate floors of the tower, to guarantee the possibility of measuring control points also on the interior spiral stairway (an architectural and structural element that highly characterize the tower). Besides, two of the ground vertices were measured also with Global Navigation Satellite System (GNSS) static technique, to georeference the reference network with respect to WGS84 Datum (UTM Zone 32N coordinates). Some of the measurement phases are shown in Figure 3. The choice of using only two vertices for georeferencing the topographic network was conditioned by the urban conformation of the area that does not allow to reach a good intervisibility between the interior part of the tower and the surrounding area. Moreover, due to the proximity between buildings in this area few locations were suitable to offer good satellite visibility. However, the data from the Continuously Operating Reference Stations (CORS) network available near this area were used to strengthen the network geometry and its computation.

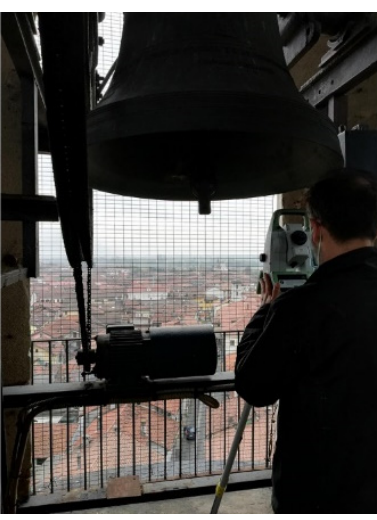

(a)

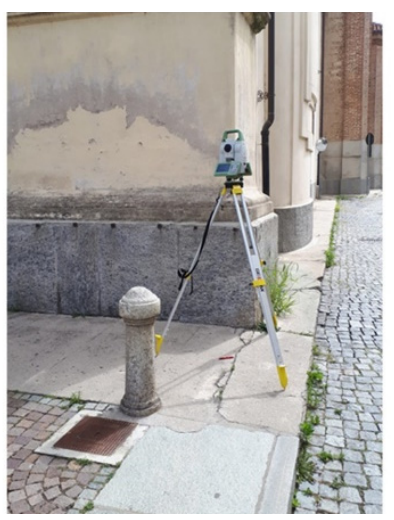

(b)
Figure 3: Some of the topographic measurements during fieldwork: a) from the belltower; b) from the area underneath

The second step of fieldwork consisted in the measurement of a set of control points with centimeter accuracy on the overall external surfaces of the tower to support the subsequent phases of data processing and accuracy assessment of the metric survey. A set of control points was also measured on the internal section of the tower to be used for the acquisitions performed in the spiral stairway; 98 control points were measured both outdoor and indoor.

During the phases of topographic measurement, several other geospatial data were acquired: UAVs photogrammetric flights, TLS acquisition, SLAM based acquisition and finally $360^{\circ}$ acquisitions.

UAVs acquisitions were performed with manual flights, due to the object structure and its location in the centre of a dense urban area. A total of 543 images, both nadiral and oblique, was acquired with the DJI Phantom 4 Pro, 
with a flight scheme parallel to each one of the tower facades and maintaining an average sensor - object distance of $5 / 6$ meters with the goal to have an average GSD of $0.003 \mathrm{~m}$. The acquisition scheme adopted during the flights is shown in Figure 4 while the main specifications of the Phantom 4 Pro camera are reported in Table 1. The flight plans were designed following consolidated approaches of the authors' research group, well documented in the literature (e.g. Achille et al., 2015; Calantropio, Chiabrando, Rinaudo, \& Teppati Losè, 2018; Murtiyoso, Grussenmeyer, \& Freville, 2017).

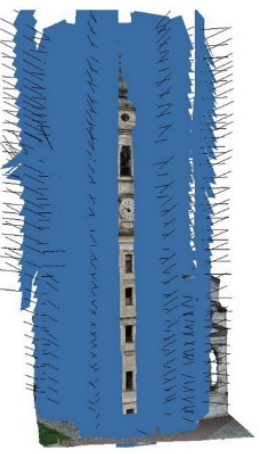

(a)

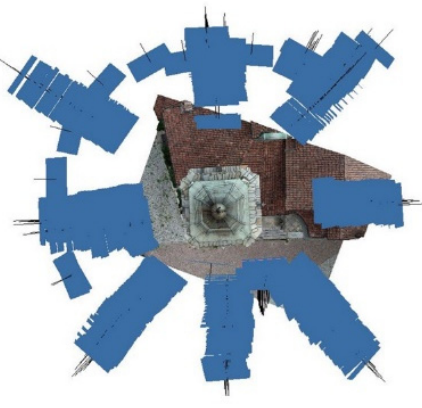

(b)
Figure 4: Acquisition scheme for the UAV flights (blue polygons are the scaled sensor frame, black lines the sensor position and attitude): a) Side view; b) top view.

Table 1: Main specifications of the DJI Phantom 4 Pro.

\begin{tabular}{c|c|c|c} 
Sensor & $\begin{array}{c}\text { Size } \\
(\mathrm{MP})\end{array}$ & $\begin{array}{c}\text { Focal length } \\
(\mathrm{mm})\end{array}$ & $\begin{array}{c}\text { Max image } \\
\text { dimension (pix) }\end{array}$ \\
\hline CMOS 1" & 20 & $24(35 \mathrm{eq})$ & $4864 \times 3648$
\end{tabular}

Traditional TLS acquisitions were completed using a Faro Focus $^{3 \mathrm{D}}$ X330. Scans positions and acquisition parameters were designed to cover the external square and part of the interior of the tower with eleven scans. Seven indoor scans were intended as a further ground truth element to validate the accuracies of other datasets and of the traditional 2D drawings, especially the horizontal and vertical cross-sections. Scan positions are shown in Figure 5 while the main specifications of the Focus $^{3 \mathrm{D}}$ X330 TLS are reported in Table 2. Due to accessibility and other operational constraints, it was not possible to perform a complete acquisition of the interior part of the tower, however, the data collected on the field are sufficient to work as ground truth reference, thanks also to the homogenous distribution of the control points.

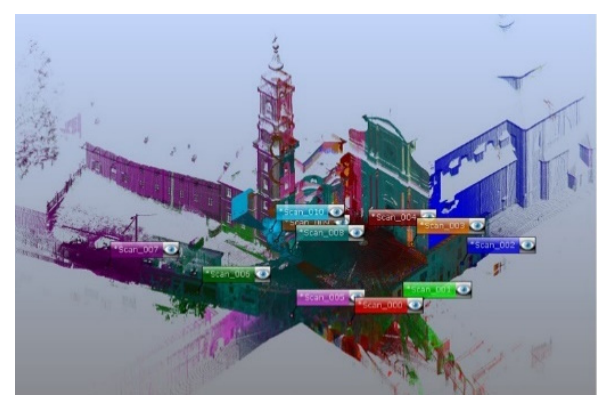

(a)

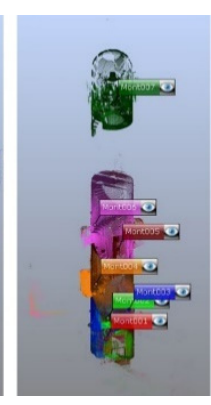

(b)
Figure 5: Scan position of the scans acquired on the field: a) bird's eye view; b) view of the interior of the tower.
Table 2: Main specifications of the Faro Focus X330.

\begin{tabular}{c|c|c|c} 
Range $(m)$ & $\begin{array}{c}\text { Measurement } \\
\text { Speed (pps) }\end{array}$ & $\begin{array}{c}\text { Ranging } \\
\text { error }(\mathrm{mm})\end{array}$ & Field of View \\
\hline $0.6-330$ & 976,000 & \pm 2 & $300 / 360^{\circ}$
\end{tabular}

Other range-based acquisitions were completed using the Zeb Revo RT system that is based on the SLAM technology. This relatively new technology has proven its efficiency also in the field of cultural heritage documentation as reported for example in (Chiabrando, Della Coletta, Sammartano, Spanò, \& Spreafico, 2018; Otero, Lagüela, Garrido, \& Arias, 2020; Tucci, Visintini, Bonora, \& Parisi, 2018). Four different acquisitions were carried out performing closed-loop, as suggested by the best practices for using this system (Riisgaard \& Blas, 2004) and testing different paths starting outdoor and covering indoor up to the higher accessible area. An example of two different scans performed with the Zeb Revo is shown in Figure 6 while the main specifications of the system are reported in Table 3.

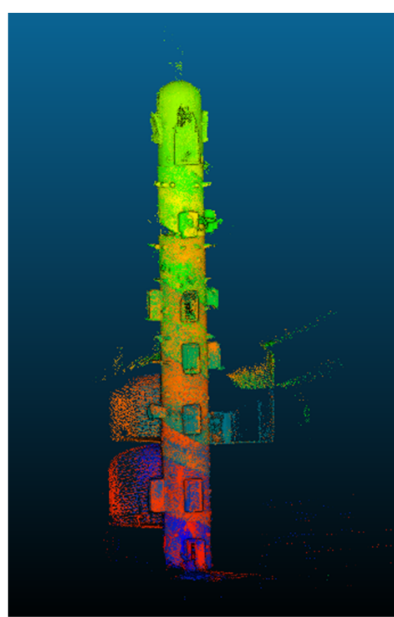

(a)

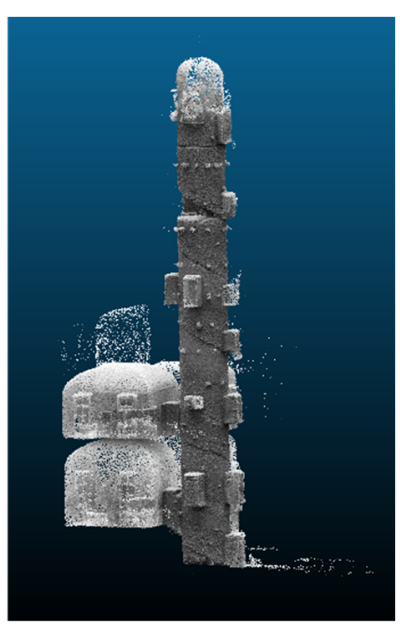

(b)
Figure 6: Example of two different scans completed with the Zeb Revo system: a) south view; b) west view.

Table 3: Zeb Revo main specifications.

\begin{tabular}{c|c|c|c} 
Range $(m)$ & $\begin{array}{c}\text { Measurement } \\
\text { Speed (pps) }\end{array}$ & $\begin{array}{c}\text { Relative } \\
\text { accuracy } \\
(\mathrm{cm})\end{array}$ & $\begin{array}{c}\text { Field of } \\
\text { View }\end{array}$ \\
\hline $15-30$ & $\sim 43,200$ & $1-3$ & $270^{\circ} / 100^{\circ}$
\end{tabular}

For the $360^{\circ}$ acquisition two different cameras were tested: the GoPro Fusion and the Kandao Qoocam 8k. The two cameras have similar specifications, except for the maximum resolution achievable: $5.2 \mathrm{k}$ for the GoPro and $8 \mathrm{k}$ for the Kandao. The same acquisition path was adopted for both cameras: a round-trip walk from outside the tower up to the highest accessible area, the bell chamber. For each camera a video at maximum resolution was recorder with an average duration of 7 minutes. An example of a spherical images acquired with the GoPro Fusion is shown in Figure 7 while the main specifications of the two cameras are reported in Table 4. After its first development (D'Annibale \& Fangi, 2009; Fangi, 2007; Fangi \& Nardinocchi, 2013) spherical photogrammetry is facing a second development phase thanks to the enhancement of the Structure from Motion (SfM) approaches, as demonstrated by recent literature (Abate, Toschi, Sturdy-Colls, \& Remondino, 2017; 
Barazzetti, Previtali, \& Roncoroni, 2018; Fangi, Pierdicca, Sturari, \& Malinverni, 2018; Gottardi \& Guerra, 2018; Teppati Losè, Chiabrando, \& Spanò, 2018).

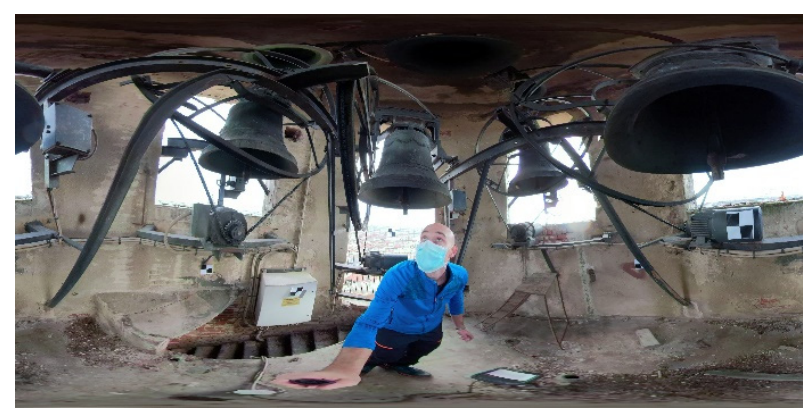

Figure 7: Example of spherical images (equirectangular projection) acquired in the bell tower with the GoPro Fusion.

Table 4: Main specifications of the two $360^{\circ}$ cameras used in the documentation project.

\begin{tabular}{c|c|c} 
Camera & Sensor & Max video resolution \\
\hline GoPro Fusion & CMOS & $5.2 \mathrm{~K} \mathrm{(5228^{ \star } 2 6 2 4 -}$ \\
& $1 / 2.3 "$ & $30 \mathrm{fps})$ \\
Kandao Qoocam 8k & CMOS & $8 \mathrm{~K}\left(7680^{\star} 3840-30 \mathrm{fps}\right)$ \\
& $1 / 2.3 "$ &
\end{tabular}

\section{Data processing and results}

The acquired data were processed following consolidated workflows that will be briefly described in the following section. UAVs collected images were processed in a wellknown SfM software (Agisoft Metashape) following the standard pipeline: image matching and tie points extraction, Bundle Block Adjustment (BBA), densification and generation of added value products such as Digital Surface Model (DSM) and orthophoto. The results of the photogrammetric processing are reported in Table 5; a small portion of the derived 3D model is shown in Figure 8 , demonstrating the very high level of detail.

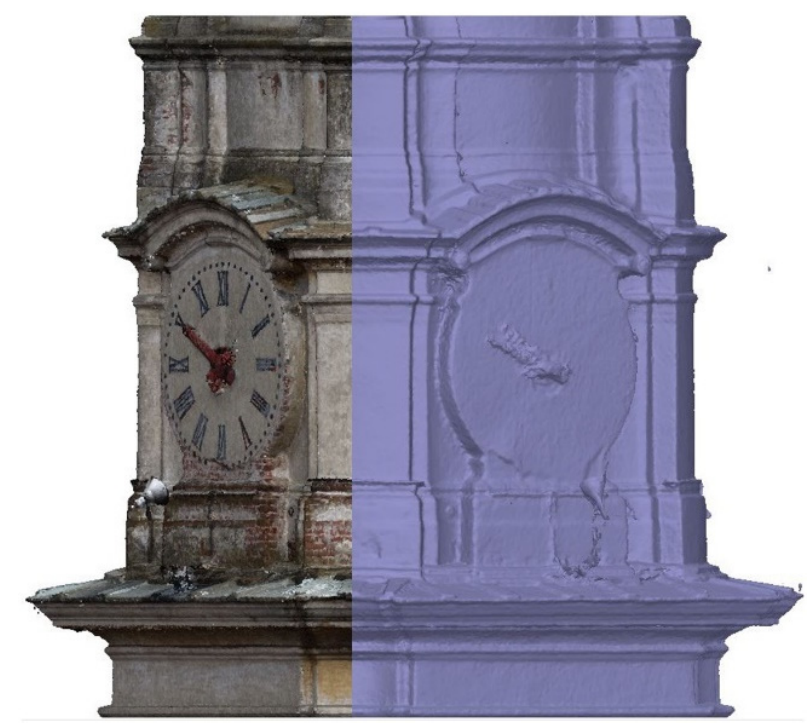

Figure 8: Portion of the 3D model derived from the UAVs dataset processing: point cloud (left with RGB value) and mesh model (right in violet).
Table 5: UAVs photogrammetric processing main results.

\begin{tabular}{c|c|c|c|c|c} 
Images & \multicolumn{2}{|c|}{ GCPSs } & \multicolumn{2}{|c|}{ CPS } & $\begin{array}{c}\text { GSD } \\
(\mathrm{m})\end{array}$ \\
& $N^{\circ}$ & $\begin{array}{c}3 D \text { RMSe } \\
(\mathrm{m})\end{array}$ & $N^{\circ}$ & $\begin{array}{c}3 D \text { RMSe } \\
(\mathrm{m})\end{array}$ & \\
\hline 543 & 27 & 0.009 & 8 & 0.008 & 0.003
\end{tabular}

The TLS dataset was processed inside the software Faro SCENE and two different approaches were followed for the outdoor and indoor dataset, as reported in (Chiabrando, Spanò, Sammartano, \& Teppati Losè, 2017). The outdoor scans were firstly registered using an Iterative Closest Points (ICP) algorithm and then georeferenced using the available control points measured. For the indoor dataset, the control points were used for both the registration and georeferencing phase, due to the different and more complex geometry of the scan positions influenced by the environmental constraints. The results of the processing of the two datasets are reported in Table 6.

Table 6: TLS dataset processing main results.

\begin{tabular}{c|c|c|c}
$\begin{array}{c}\text { Scan } \\
\text { Group }\end{array}$ & $\begin{array}{c}\text { Number } \\
\text { of scans }\end{array}$ & $\begin{array}{c}\text { Mean scan points } \\
\text { tension }(\mathrm{m})\end{array}$ & $\begin{array}{c}\text { Mean Target } \\
\text { tension }(\mathrm{m})\end{array}$ \\
\hline Outdoor & 11 & 0.002 & 0.013 \\
Indoor & 7 & n.a. & 0.004
\end{tabular}

As regards the scans acquired with the ZEB Revo RT through the use of SLAM-based algorithms, an optimization of the four-point clouds is required (before proceeding with the registration of the point clouds in the same reference system adopted for the other data collected during the survey).

During the data processing phase, the data derived from the ZEB Revo RT were processed using the GeoSLAM Hub platform following the standard workflow.

After a preliminary procedure during which the different point clouds have been roughly manually aligned, the four acquisitions have been processed with the "merge" function of the GeoSLAM Hub platform. This process allows us to join the different scans in the same relative reference system; besides, an optimization of the point cloud is performed in order to improve the quality of the finals results. The "merge" function allows fixing the possible misalignments and the drifts errors affecting the raw scan, which are, in many cases, not detectable through a simple visual inspection. In fact, besides the high complexity of the surveyed tower, one of the reasons why different point clouds have been acquired characterized by a high reciprocal overlapping - is due to the possibility to optimize each of the acquired point clouds. During this phase, following the standard processing strategy adopted ZEB Revo RT, a coregistration between scans is performed by non-rigid transformation. For every scan involved in the merge reprocessing, the SLAM algorithm is recomputed, mutually using the features of the adjacent cloud, in order to solve the aforementioned misalignment issues.

At the end of these optimization procedures, the data was then registered using as reference the indoor LiDAR scans, to align the point cloud acquired with the ZEB Revo $\mathrm{RT}$ in the reference system of the point clouds generated using the other sensors. An ICP registration has been performed using the open-source platform CloudCompare (Fig. 9a). The RMSE (Root mean square 
error) observable at the end of the ICP registration is approximately around $4 \mathrm{~cm}$. In order to check the final accuracy of the acquired data, a distance analysis has been carried out between the two datasets (LIDAR and ZEB) in the considered area of overlapping. As observed in Figure 9b, it is possible to see that the discrepancies are lower than $5 \mathrm{~cm}$ in approximately $85 \%$ of the SLAM dataset).

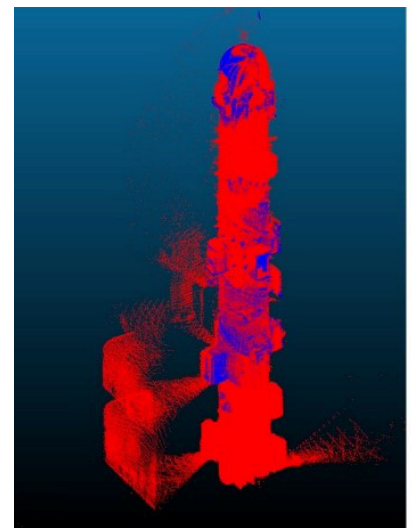

(a)

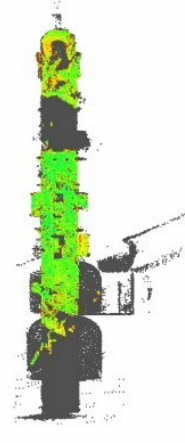

(b)
Figure 9: C2C: a) ICP registration between LiDAR point cloud (ground truth reference, blue point cloud) and data derived from ZEB Revo RT (aligned scan, red point cloud); b) Discrepancies between the LiDAR point cloud and the registered ZEB Revo RT scan.

Lastly, the processing of the $360^{\circ}$ dataset required a less consolidated approach, due to the recent new developments of spherical photogrammetry. The first step consisted in the extraction of a series of frames from the $360^{\circ}$ videos (one out of 30 , i.e. around 1 frame/second considering the data were acquired at $30 \mathrm{fps}$ ) that were then processed inside Agisoft Metashape. Spherical photogrammetry is nowadays challenging under several aspects and despite tailored tests are still ongoing, the first outcomes are encouraging. The main parameters of the processing of spherical data are reported in Table 7 while an extract of the acquisition geometry is shown in Figure 10. For the purposes of this contribute only the dataset derived from the GoPro Fusion is reported and discussed. Tests and analyses on the dataset acquired with the Qoocam $8 \mathrm{~K}$ are still under development and will be part of a wider research on the accuracy assessment and best practices on the use of $360^{\circ}$ cameras for the documentation of cultural heritage.

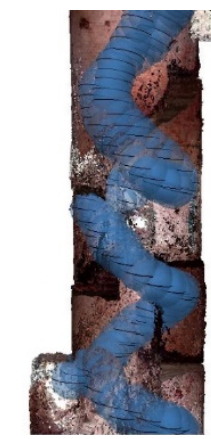

Figure 10: Extract of the acquisition geometry of the $360^{\circ}$ dataset (blue spheres represent camera position, black letters are the name of the single images).
Table 7: Spherical photogrammetry processing main results.

\begin{tabular}{c|c|c|c|c|c} 
Images & \multicolumn{2}{|c|}{ GCPSs } & \multicolumn{2}{c|}{ CPS } & $\begin{array}{c}\text { Average } \\
\text { GSD } \\
(\mathrm{m})\end{array}$ \\
\hline 319 & 17 & 0.048 & 5 & 0.054 & 0.002 \\
& $N^{\circ}$ & $\begin{array}{c}3 D \\
(\mathrm{~m})\end{array}$ & $N^{\circ}$ & $\begin{array}{c}3 D \mathrm{RMSe} \\
(\mathrm{m})\end{array}$ &
\end{tabular}

However, some preliminary analyses were conducted on the point cloud derived from the GoPro Fusion spherical images photogrammetric processing to start evaluating its accuracy and validating its use in this specific documentation project. A first analysis of the $360^{\circ}$ point cloud was performed with the 3D Reshaper software: a Cloud to Cloud (C2C) distance analysis was carried out using the TLS point cloud as reference. This analysis was performed only on a small portion of the point clouds: a graphical representation of the point cloud distances is shown in Figure 11, while the percentages of the points that are included in different ranges of distances are reported in Table 8.

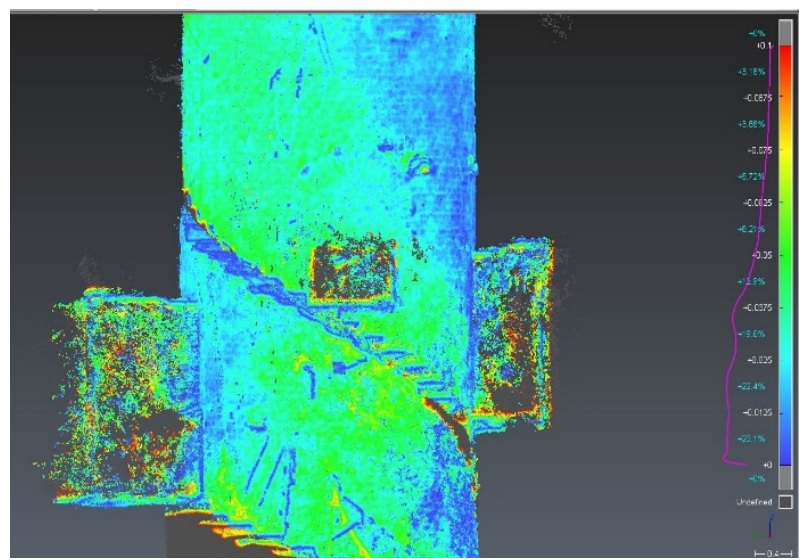

Figure 11: C2C distance analysis between the TLS and $360^{\circ}$ derived point cloud.

Table 8: C2C comparison between TLS and spherical point clouds.

\begin{tabular}{c|c} 
Ranges of distances $(m)$ & Percentages of the points \\
\hline $0.00-0.02$ & $37 \%$ \\
$0.02-0.04$ & $32 \%$ \\
$0.04-0.06$ & $17 \%$ \\
$0.06-0.10$ & $14 \%$
\end{tabular}

It is interesting to notice that, at least for the portion of the $360^{\circ}$ point cloud considered in this analysis, almost $70 \%$ of points presents a deviation from the TLS point cloud that is less than $0.04 \mathrm{~m}$, confirming the accuracy of the photogrammetric processing that was already declared for the GCPS RMSE in Table 7.

Another type of analysis was performed on the 2D polyline derived from a thin horizontal section of the different point clouds and was aimed to verify the geometrical accuracy of the two rapid mapping approaches tested for the documentation of the bell tower. For this analysis, the same thin horizontal section (0.007 $\mathrm{m}$ width) was replicated in three different point clouds: TLS, SLAM and $360^{\circ}$ derived using the PointCab software. From these sections, three different horizontal profiles were drawn in a CAD environment (the subjectivity introduced by the human intervention shall be taken into account in these analyses) and then compared 
inside the 3D Reshaper software. Also for this analysis, the TLS data was used as a reference and it was then possible to compare the other two datasets with the TLS. The plot of the distances between different horizontal profiles as shown in Figure 12.

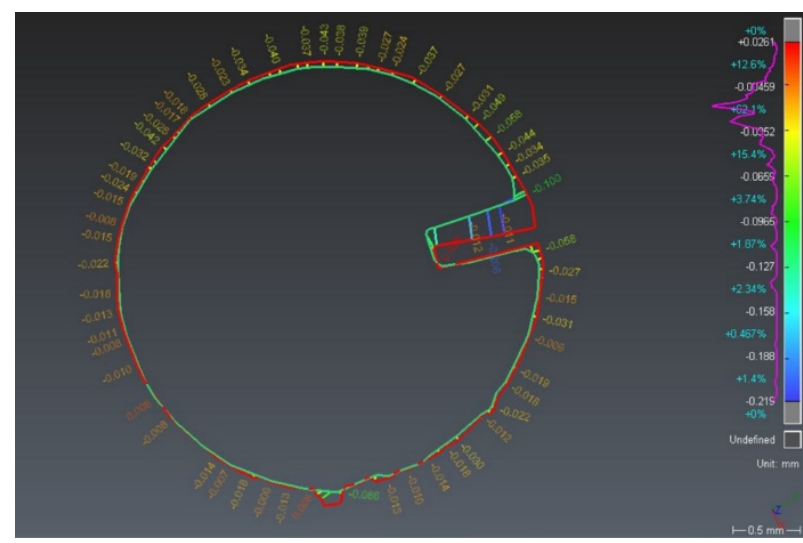

(a)

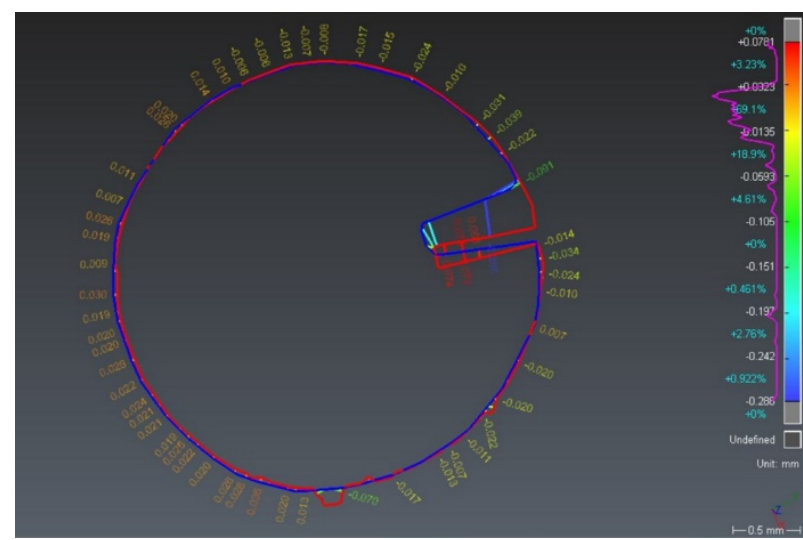

(b)

Figure 12: Distance analyses between 2D horizontal profiles derived from thin sections of the different point clouds. Red lines are extracted from the TLS dataset, green line (a) is extracted from $360^{\circ}$ dataset while the blue one (b) is extracted from the SLAM dataset)

\section{Generation of the required metric products}

One of the deliverables planned for the documentation project is the generation of traditional $2 \mathrm{D}$ architectural drawings to support further decay analyses and future restoration projects. This work is generally a timeconsuming operation that requires a large effort from the involved operators. In the presented experience it was made more difficult from the structure of the tower and its morphological complexity. Overall, this step was successfully completed in a reasonable amount of time thanks to the integration between the different datasets acquired and processed that allowed representing all the architectonical features and principal characteristics of the bell tower. Moreover, the availability of the $360^{\circ}$ videos allowed a visual immersive inspection of the tower enabling a virtual survey to visually inspect the area of interest and solving any possible interpretation doubt in the architectural drawing phase. Several drawings were then realized, enriched also from the radiometric content of the orthoimagery, as shown in Figure 13. Despite the delivery of the aforementioned products in a GeoPDF format enables end-user to perform additional spatial analysis (e.g. 3D measures) or to fine-tune how to display the architectural drawings (e.g. switching layers on and off), further experimentations are under development to test different solution for an easier and more effective exploitation of the added value products from the enduser perspective (i.e. restorers in this case). This goal can be achieved by taking advantage of different web applications, which deployment will be better described in a future contribute, and that allows to share different types of contents such as 3D models or spherical images/videos.

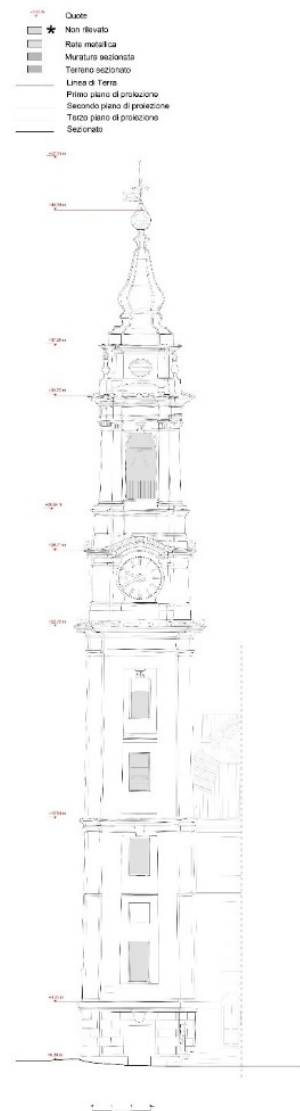

(a)

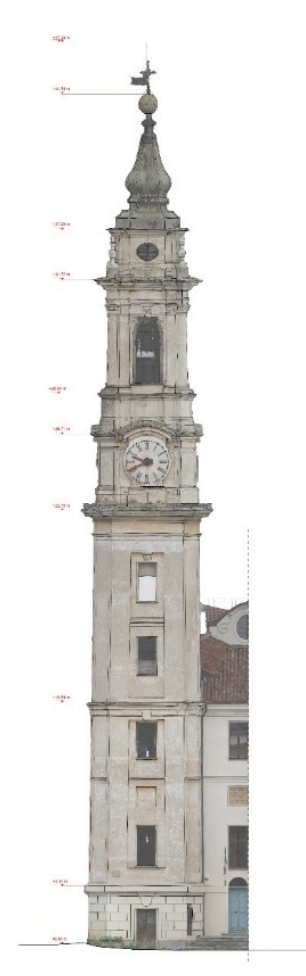

(b)
Figure 13: Example of one of the 2D architectural drawing (south facade): a) based on the $3 \mathrm{D}$ integrated survey; b) overlayed with the orthoimage.

\section{Conclusions and further perspectives}

The documentation project of the Montanaro bell tower represents a good opportunity to showcase the crucial role of geomatics in supporting the restoration domain thanks to an interdisciplinary approach.

Geomatics experts can design the proper 3D survey only by means of effective interaction with the restoration experts, understanding the specific requirements especially in terms of accuracy, level of detail and final products.

In this specific case study, the peculiar conformation of the bell tower, especially the indoor spiral stairway, and its value as heritage assets, represented the perfect test 
field to adopt and test cutting edge 3D survey approaches.

The two more consolidated approaches, UAV and TLS acquisitions, have been successfully deployed for the acquisition of geospatial data and the generation of added value products with the proper 3D accuracy level. In parallel, they have been flanked by two additional experimental approaches: handheld laser based on the SLAM technology and spherical photogrammetry.

Mobile Mapping Systems are more developed if compared with spherical photogrammetry, however, their deployment in the field is still characterized by some issues (e.g. the georeferencing of the acquired data, the association of RGB values to the SLAM point cloud, the metrical and geometrical accuracy) that need to be further analysed, especially if connected with the documentation of cultural heritage.

Spherical photogrammetry has raised new interest in the geomatics community in the last few years thanks to the latest development of SfM algorithms that allowed to effectively process also this category of images. The accuracy and robustness of these approaches still need to be validated, as well as the most efficient strategies to adopt for their processing. In the planned development of this research project, the difference between the two tested $360^{\circ}$ cameras will be evaluated; different processing solutions will be tested (stitched or single images) and the results will be further compared with more consolidated techniques adopted as ground truth.

Lastly, it has to be remarked that a streamlined sharing and remote access to survey-based 3D data is a trending topic of high interest for several application domains and research communities, also due to the movement limitations imposed by the Covid-19 pandemic emergency in 2020.

\section{Acknowledgements}

The authors would like to acknowledge the Montanaro Municipality for its availability and support in all the fieldwork phases. The authors would also like to thank Prof. Fabio Giulio Tonolo for the support during the field activities and the review of the draft manuscript.

\section{References}

Abate, D., Toschi, I., Sturdy-Colls, C., \& Remondino, F. (2017). A low-cost panoramic camera for the 3d documentation of contaminated crime scenes. International Archives of the Photogrammetry, Remote Sensing and Spatial Information Sciences - ISPRS Archives, 42(2W8), 1-8. https://doi.org/10.5194/isprs-archives-XLII-2-W8-1-2017

Achille, C., Adami, A., Chiarini, S., Cremonesi, S., Fassi, F., Fregonese, L., \& Taffurelli, L. (2015). UAV-Based Photogrammetry and Integrated Technologies for Architectural Applications-Methodological Strategies for the After-Quake Survey of Vertical Structures in Mantua (Italy). Sensors, 15(7), 15520-15539. https://doi.org/10.3390/s150715520

Barazzetti, L., Previtali, M., \& Roncoroni, F. (2018). Can we use low-cost 360 degree cameras to create accurate 3D models? In International Archives of the Photogrammetry, Remote Sensing and Spatial Information Sciences ISPRS Archives, 42, 69-75. https://doi.org/10.5194/isprs-archives-XLII-2-69-2018

Battaglio, M. (2000). L'ultimo Vittone. Il campanile di Montanaro nuovi rilievi e fonti d'archivio. Edizioni Litoart, Torino 2000.

Calantropio, A., Chiabrando, F., Rinaudo, F., \& Teppati Losè, L. (2018). Use and evaluation of a short range small quadcopter and a portable imaging laser for built heritage 3D documentation. In International Archives of the Photogrammetry, Remote Sensing and Spatial Information Sciences - ISPRS Archives, 42, 71-78. https://doi.org/10.5194/isprs-archives-XLII-1-71-2018

Canavesio, W. (2005). Il voluttuoso genio dell'occhio. Nuovi studi su Bernardo Antonio Vittone. Ages Arti Grafiche, Torino 2005.

Chiabrando, F., Della Coletta, C., Sammartano, G., Spanò, A. T., \& Spreafico, A. (2018). "TORINO 1911" project: A contribution of a SLAM-based survey to extensive 3D heritage modeling. In International Archives of the Photogrammetry, Remote Sensing and Spatial Information Sciences - ISPRS Archives, 42, $225-234$. https://doi.org/10.5194/isprs-archives-XLII-2-225-2018

Chiabrando, F., Spanò, A. T., Sammartano, G., \& Teppati Losè, L. (2017). UAV oblique photogrammetry and LiDAR data acquisition for 3D documentation of the Hercules Fountain. Virtual Archaeology Review, 8(16), 83. https://doi.org/10.4995/var.2017.5961

D’Annibale, E., \& Fangi, G. (2009). Interactive Modelling by Projection of Oriented Spherical Panorama -- Ad Deir, Petra, Jordan. In 3D-ARCH 2009: $3 D$ Virtual Reconstruction and Visualization of Complex Architectures XXXVIII. https://doi.org/10.1007/s00421-007-0565-x

Fangi, G. (2007). The Multi-image spherical Panoramas as a tool for Architectural Survey. XXI International CIPA Symposium, (October), 0256--1840.

Fangi, G., \& Nardinocchi, C. (2013). Photogrammetric processing of spherical panoramas. Photogrammetric Record, 28(143), 293-311. https://doi.org/10.1111/phor.12031

Fangi, G., Pierdicca, R., Sturari, M., \& Malinverni, E. S. (2018). Improving spherical photogrammetry using $360^{\circ} \mathrm{OMNI-}$ Cameras: Use cases and new applications. In International Archives of the Photogrammetry, Remote Sensing and Spatial Information Sciences - ISPRS Archives, 42, 331-337). https://doi.org/10.5194/isprs-archives-XLII-2-3312018 
Gottardi, C., \& Guerra, F. (2018). Spherical images for cultural heritage: Survey and documentation with the NIKON KM360. In International Archives of the Photogrammetry, Remote Sensing and Spatial Information Sciences - ISPRS Archives, 42, 385-390. https://doi.org/10.5194/isprs-archives-XLII-2-385-2018

Murtiyoso, A., Grussenmeyer, P., \& Freville, T. (2017). Close range uav accurate recording and modeling of St-Pierre-LeJeune Neo-Romanesque church in Strasbourg (France). International Archives of the Photogrammetry, Remote Sensing and Spatial Information Sciences - ISPRS Archives, 42(2W3), 519-526. https://doi.org/10.5194/isprsarchives-XLII-2-W3-519-2017

Otero, R., Lagüela, S., Garrido, I., \& Arias, P. (2020). Mobile indoor mapping technologies: A review. Automation in Construction. Elsevier B.V. https://doi.org/10.1016/j.autcon.2020.103399

Portoghesi, P. (1966). Bernardo Vittone. Un architetto tra Illuminismo e Rococò, Ed. dell'Elefante, Roma, 1966.

Riisgaard, S., \& Blas, M. R. (2004). SLAM for Dummies. Massachusetts Institute OfTechnology Projects, 1-127.

Teppati Losè, L., Chiabrando, F., \& Spanò, A. (2018). Preliminary evaluation of a commercial 360 multi-camera RIG for photogrammetric purposes. In International Archives of the Photogrammetry, Remote Sensing and Spatial Information Sciences - ISPRS Archives , 42, 1113-1120). https://doi.org/10.5194/isprs-archives-XLII-2-1113-2018

Tucci, G., Visintini, D., Bonora, V., \& Parisi, E. (2018). Examination of Indoor Mobile Mapping Systems in a Diversified Internal/External Test Field. Applied Sciences, 8(3), 401. https://doi.org/10.3390/app8030401 